\title{
Bruce A. Blonigen and Wesley W. Wilson (Editors): Handbook of International Trade and Transportation
}

\author{
Publisher: Edward Elgar Publishing, 2018, Cheltenham, UK; \\ Northampton, Massachusetts, USA. \\ ISBN 978-1-78536-614-7
}

This book is a collection of works by 50 authors, edited by Bruce A. Blonigen and Wesley W. Wilson, from the University of Oregon, USA. This book presents two closely related topics, international trade and transport in one place. Academic literature has traditionally described these two phenomena separately. In the Handbook of International Trade and Transportation, these topics are presented in one place, which is a great novelty.

The fascinating growth of world trade over the last few decades justifies the great interest of many leading world authors for these issues. In the last half century (19602015) the volume of world trade has increased 30 times (GDP has grown by a factor of nearly 10 since the early 1960s).

Numerous technological and structural changes have contributed to this growth in the volume of world trade. The introduction of containers in the 1950s and other technological innovations and the construction of new infrastructure (construction of large ships, new ports and modern port infrastructure, construction of modern transport networks, etc.) enabled the greatest growth rates of international trade in the history of human civilization.

During this period, container traffic grew at an average annual rate of $11.9 \%$, and other transport modes were driven by it. This Handbook basically links key findings in the field of international trade and transport. Adequate attention is provided to well-known knowledge, but new areas such as the influence of international trade and transport on the environment are opened.

The book is structured in six sections and 23 chapters.

Chapters in Part I present the latest data and modeling techniques used to explain global trade patterns. This section begins with chapter about the gravity trade equation, the fundamental empirical specification in the international trade literature that so robustly explains trade patterns among regions and countries in the world. Next chapter provides a variety of useful extensions to the model, including accounting 
for endogeneity, internal (national) flows of goods, and missing or zero trade flows.

After this initial context of global trade and transportation, in Part II there are 5 chapters addressing the core theme of the Handbook: the intersection of international trade and transportation costs. Particularly interesting in this section are chapters dealing with empirical literature on the role of transport costs.

Increased levels of globalization and specialization led to an increasing important of international trade and new structural changes in production and consumption. When the prices of two substitute goods, such as high and low grades of the same product, are both increased by a fixed per-unit amount such as a transportation cost or a lump-sum tax, consumption will shift toward the higher-grade product. This is true because the added per-unit amount decreases the relative price of the higher-grade product (Alchian-Allen hypothesis).

An important chapter in this section examines an issue of increasing concern for transportation of internationally traded goods - environmental costs. The chapter provides a thorough primer on the many ways in which international transport can have environmental impact, as well as the evolution of policy in this area and responses by shippers in response to these policies. It concludes by describing a number of innovative practices that could help transport reduce environmental costs, including optimal speeds, new way of intermodal connection and synchronizing supply chains. The future of this strategies and consequences is very important and open for new research.

The next two parts of the book explore the micro-foundations of international trade and transport. Traditional models of international trade had a focus on cross-country or cross-region trade patterns. However, countries do not directly trade with each other; firms and individuals do. In Part III we find out about the agents that are important for international trade and transactions. Part IV examines how those agents negotiate the logistics of transporting goods across international borders. The quality of the transportation infrastructure is very important for countries and companies which participate in international trade. This is the main subject on chapters in Part V.

The final part of the Handbook, Part VI, features chapters examining the network attributes of the international transportation system. The exact spatial aspects of a system of trade routes (formed by geographic features, policy, and other factors) have major implications for key issues, including the efficiency of trade flows and the equity of service across all nodes of the network.

The book will be extremely useful to economists and experts in other areas who want to understand the phenomena of international trade and transport in all aspects.

Vladimir Čavrak

Faculty of Economics and Business, University of Zagreb, Zagreb, Croatia 